\title{
BIMBINGAN TEKNIS DESAIN DAPUR PEMANAS MODEL TERTUTUP DAN CEROBONG GANDA PADA MANAJEMEN BISNIS UKM PANDAI BESI WILAYAH DISPERINDAG KABUPATEN MALANG
}

\author{
Djoko Andrijono'), Sufiyanto ${ }^{2)}$ \\ ${ }^{1,2)}$ Fakultas Teknik, Universitas Merdeka Malang \\ 1) Email: djoko.andrijono@unmer.ac.id \\ ${ }^{2)}$ Email: sufiyanto@unmer.ac.id
}

\begin{abstract}
Abstrak
Uji coba dapur pemanas terbuka dengan ukuran panjang $1100 \mathrm{~mm}$, lebar $900 \mathrm{~mm}$, tinggi $700 \mathrm{~mm}$ dan dinding terbuat dari bahan bata tahan api dan bata merah mampu menghasilkan temperatur panas $925^{\circ} \mathrm{C}$ dibanding dengan dapur pemanas tertutup hanya mampu menghasilkan temperatur panas $720^{\circ} \mathrm{C}$. Hasil uji kekerasan setelah logam ditempa panas dan dilanjutkan proses pendinginan oli, angka kekerasan tertinggi pada pendinginan oli SAE 40 sebesar $88 \mathrm{HR}_{\mathrm{B}}$ dan angka kekerasan terendah pada pendinginan oli SAE 140 sebesar $85 \mathrm{HR}_{\mathrm{B}}$. Angka kekerasan semakin menurun disebabkan viskositas oli semakin kental, akibatnya laju pendinginan semakin lambat dan besar butirnya semakin kasar, sehingga logam mudah ditempa panas. Pengamatan struktur mikro pada bagian permukaan logam hasil tempa panas pendinginan oli dengan pembesaran $200 \mathrm{x}$ secara umum lebih dominan terbentuk fasa ferit dibanding fasa perlit dan bagian melintang logam hasil tempa panas pendinginan oli dengan pembesaran $200 \mathrm{x}$, secara umum baja karbon rendah dan baja karbon tinggi telah menyatu. Fasa ferit sifatnya ulet, kekerasannya rendah dan fasa perlit sifatnya keras tetapi getas. Pada pendinginan oli tidak terbentuk fasa martensit yang sifatnya sangat keras dan getas, hal ini disebabkan pada saat proses pendinginan seluruh jenis oli fasa austenit tidak dapat bertransformasi menjadi fasa martensit.
\end{abstract}

Kata kunci: dapur pemanas tertutup, temperatur, kekerasan

\section{PENDAhUluan}

\section{a. Analisis Situasi}

Wilayah Kabupaten Malang terletak antara $112^{\circ} 17^{\prime} 10,90^{\prime \prime}-112^{\circ} 57^{\prime} 00,00^{\prime \prime}$ Bujur Timur, $7^{\circ} 44^{\prime} 55,11^{\prime \prime}-8^{\circ} 26^{\prime} 35,45^{\prime \prime}$ Lintang Selatan. Luas wilayah 353.486 ha. Secara administratif, wilayah Kabupaten Malang terdiri dari 33 kecamatan, 12 kelurahan, 378 desa, 3.156 Rukun Warga (RW) dan 14.695 Rukun Tetangga (RT). Perkembangan penduduk Kabupaten Malang menurut data sumber perhitungan Badan Pusat Statistik Kabupaten Malang pada tahun 2016 sebesar 2.560.675 jiwa atau rata-rata pertumbuhan $0,64 \%$ per-tahun terdiri dari lakilaki 1.286 .867 jiwa $(50,25 \%)$ dan perempuan 1.273.808 jiwa $(49,75 \%)$ dengan rata-rata kepadatan $724.406 \mathrm{jiwa} / \mathrm{km}^{2}$. Jumlah penduduk menurut sumber data Dinas Kependudukan dan Pencatatan Sipil Kabupaten Malang hasil penghitungan akhir tahun 2016 adalah sebesar 2.705.395 jiwa terdiri dari laki-laki 1.365.806 jiwa $(50,48 \%)$ dan perempuan 1.339 .589 jiwa $(49,52 \%)$, sedangkan untuk komposisi Penduduk Kabupaten Malang berdasarkan jenis pekerjaan tahun 2016 sejumlah 950 jiwa yang bergerak di bidang tukang las atau pandai besi (Laporan Penyelenggaraan Pemerintahan Daerah Kabupaten Malang, 2016). Pandai besi (black smith) merupakan salah satu industri skala mikro yang harus dipertahankan dan dikembangkan agar dapat bertahan menghadapi persaingan global dan agar dapat bertahan menghadapi persaingan, maka output yang dihasilkan harus memperhatikan efisiensi dan efektifitas, efisien dari sisi biaya produksinya dan efektif dari segi target dalam arti produknya (Hana 2013, Martin et.al, 2013 dan Nouruzy et.al, 2013). Salah satu pandai besi di desa Talang Suko Kedok RT 01 RW 03 Kedok Kabupaten Malang (mitra) merupakan UKM yang sampai sekarang masih produktif dengan produk sesuai pesanan seperti: cangkul, sabit, cetok, pedang dan pisau dapur, sehingga dengan adanya UKM pandai besi dapat menciptakan lapangan pekerjaan bagi para remaja yang putus sekolah. Jumlah karyawan setiap pengrajin pandai besi rata-rata 3 s.d 4 tenaga karyawan (laki-laki) yang masing-masing mempunyai tugas dan tanggungjawab tidak sama dan didukung peralatan yang tradisional. Pendidikan karyawan terendah umumnya Sekolah Dasar dan pendidikan yang paling tinggi Sekolah Menengah Umum atau yang sederajat. Proses produksinya sangat sederhana (tradisional) dan tidak memerlukan pengetahuan khusus tetapi keterampilan sangat dibutuhkan. Proses produksi yang dilakukan pandai besi diawali dengan memanaskan dua material logam dengan komposisi kimia dan sifat kekerasan 
berbeda ke dalam dapur pemanas model terbuka (Gambar 1) secara bergantian sampai material logam berpijar menggunakan bahan bakar arang kayu jati (Gambar 2).

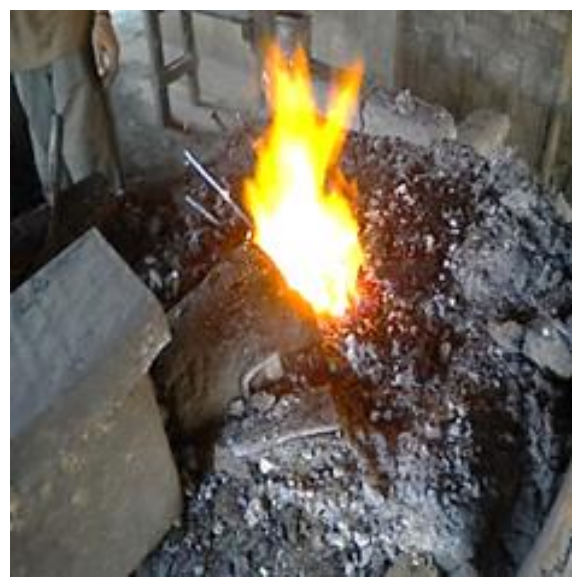

Gambar 1. Dapur Pemanas Model Terbuka

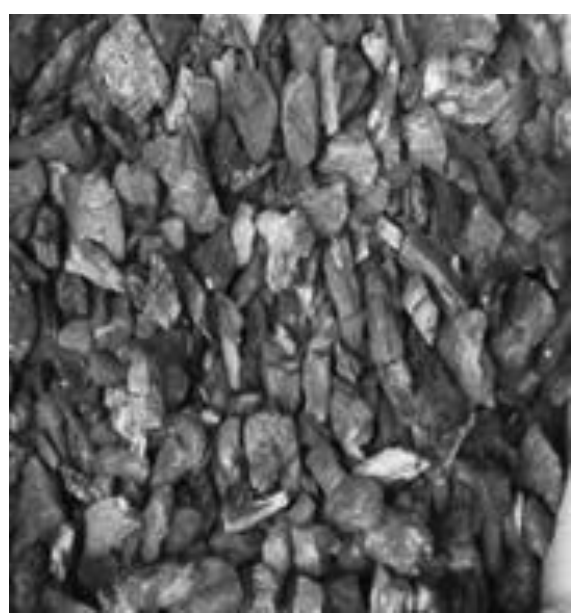

Gambar 2. Arang Kayu Jati

Arang kayu jati merupakan arang kayu tropis keras atau arang kayu jati memiliki unsur $69,8 \%$ C, kadar abu 1,2\%, nilai kalor 3.583 $\mathrm{kcal} / \mathrm{gram}$, kecepatan pembakaran 135 gram/detik, lama penyalaan sampai menjadi abu 109,45 menit. (Nabawiyah, K, dkk. 2010. Jurnal Neutrino Volume 3 Nomor 1). Material logam yang digunakan untuk proses tempa panas terdiri dari baja karbon rendah dan baja karbon tinggi (Avner, 1987) yang dipanasi secara bergantian dan selanjutnya dilakukan proses pengerjaan panas (hot working) jenis tempa panas (hot forging) di atas landasan (anvil) secara bertahap menggunakan palu (hammer) yang berfungsi untuk memberikan gaya luar (external force) (Gambar 3) dengan berat palu rata 3 s.d $5 \mathrm{~kg}$ dan dilanjutkan proses pendinginan cepat menggunakan air (quenching) (Akbar, N., dkk., 2017).

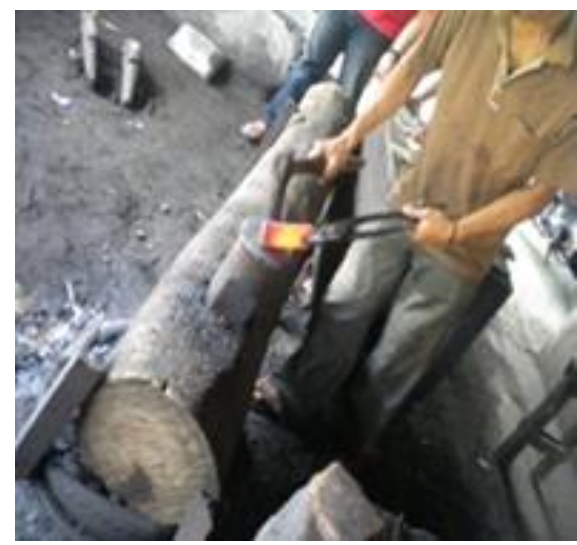

Gambar 3. Proses Tempa Panas

Proses pengerjaan panas merupakan proses deformasi pada logam yang dilakukan dengan kondisi temperatur dan laju regangan tertentu sehingga proses deformasi dan proses recovery secara bersamaan (Dieter, G,E., 1981). Pengerjaan panas dilakukan di atas temperatur rekristalisasi atau di atas daerah pengerasan kerja. Pada waktu proses pengerjaan panas berlangsung, logam berada dalam keadaan plastik dan mudah dibentuk oleh tekanan. Keuntungan proses pengerjaan panas meliputi: (a) porositas yang terjadi dalam logam dapat berkurang, (b) kebutuhan energi untuk proses tempa dalam keadaan plastis lebih rendah, dan sifat mekanis (kekerasan) dapat meningkat (Polukhin, P. 1977).

\section{b. Permasalahan yang Dihadapi Pandai Besi}

Berdasarkan hasil wawancara dan studi lapangan dengan UKM Pandai Besi di desa Talang Suko Kedok RT 01 RW 03 Kedok Kabupaten Malang (mitra) (Gambar 4).

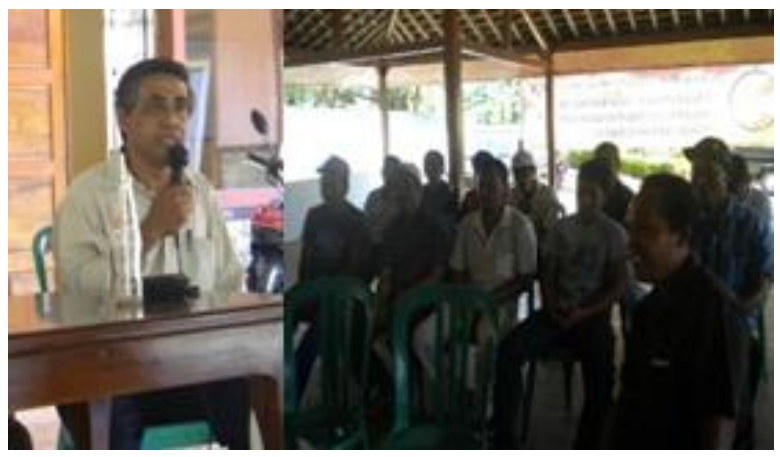

Gambar 4. Wawancara dengan UKM Pandai Besi desa

Talang Suko Kedok RT 01 RW 03 Kedok Kabupaten Malang

Identifikasi permasalahan yang disampaikan UKM Pandai Besi di desa Talang Suko Kedok RT 01 RW 03 Kedok Kabupaten Malang meliputi: 
1. Material dinding dapur pemanas

Material dinding dapur pemanas (Gambar 1) terbuat dari bata merah dengan campuran tanah liat, pasir, dan air, mengakibatkan koefisien ekspansi panas yang dihasilkan sangat tinggi, dinding dapur pemanas dengan material bata merah tidak tahan terhadap temperatur tinggi, dan bata merah tidak tahan perubahan temperatur secara mendadak (tiba-tiba), sehingga mudah retak (pecah).

2. Dapur pemanas model terbuka

Temperatur panas hasil pembakaran arang kayu jati tidak stabil untuk mencapai di atas temperatur rekristalisasi, karena daerah perapian mudah teroksidasi.

\section{METODE KEGIATAN}

Upaya untuk mengatasi permasalahan tersebut, dapat dilakukan beberapa perbaikan meliputi:

a. Perbaikan material dapur pemanas

Dengan mengganti material dapur pemanas yang dapat menurunkan angka koefisien ekspansi panas yang ditimbulkan dari hasil pembakaran arang kayu jati.

b. Perbaikan desain dapur pemanas

Memperbaiki desain dapur pemanas dengan model tertutup yang dilengkapi dengan cerobong ganda dan single blower.

Langkah-langkah untuk menwujudkan dua hal tersebut:

\section{a. Perbaikan Material Dapur Pemanas}

Perbaikan material dinding dapur pemanas (Tabel 1) dengan bata tahan api (Sugiyono, A. 2000) dengan tujuan agar koefisien ekspansi panas yang dihasilkan menjadi lebih rendah, tahan terhadap temperatur tinggi, titik lebur tinggi, kekuatan yang baik pada temperatur tinggi, tahan degradasi, tahan benturan dan abrasi, tahan siklus panas.

Tabel 1. Material Dapur Pemanas

\begin{tabular}{|c|l|c|}
\hline No & \multicolumn{1}{|c|}{ Material } & Penggunaan \\
\hline 1 & Bata merah & Dinding luar \\
\hline 2 & Semen Portland & Dinding luar \\
\hline 3 & Bata tahan api SK 34 & Dinding dapur \\
\hline 4 & Castable material & Dinding dalam \\
\hline 5 & Semen tahan api & Tutup dapur pemanas \\
\hline 6 & Blower 0,25 pk & Penghembus udara \\
\hline 7 & Besi profil L 50 x 50 (mm) & Rangka dapur pemanas \\
\hline 8 & Pipa diameter 2 inch & Cerobong asap \\
\hline 9 & Engsel & Buka tutup dapur pemanas \\
\hline 10 & Kotak kowi $500 \times 300 \times 500(\mathrm{~mm})$ & Kotak pemanas \\
\hline 11 & Tutup kotak kowi $500 \times 300 \times 500(\mathrm{~mm})$ & Tutup kotak pemanas \\
\hline
\end{tabular}

\section{b. Perbaikan Desain Dapur Pemanas}

Perbaikan desain dapur pemanas dilakukan beberapa tahapan seperti pada diagram alir (Gambar 5) berikut ini.

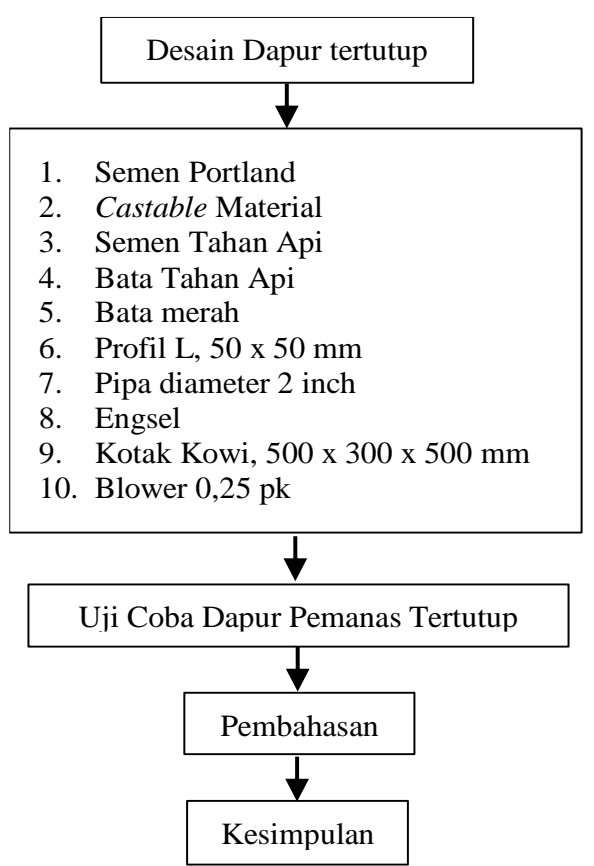

Gambar 5. Diagram Alir Proses Pembuatan Dapur Pemanas Terbuka

Untuk melakukan pembuatan dapur pemanas model tutup dan cerobong ganda diperlukan beberapa tahapan meliputi:

\section{Persiapan pengerjaan awal}

1. Pengukuran dan pemotongan rangka dapur pemanas terbuka

Rangka dapur pemanas terbuka terbuat dari material besi profil L berukuran $50 \times 50 \mathrm{~mm}$ dan material tersebut diukur menggunakan rollmeter yang selanjutnya dipotong-potong menggunakan mesin gergaji (Gambar 6) dan digerinda tangan (Gambar 7) dengan ukuran sebagai berikut: panjang $1100 \mathrm{~mm}$ sebanyak 4 batang, lebar $900 \mathrm{~mm}$ sebanyak 4 batang dan tinggi $700 \mathrm{~mm}$ sebanyak 4 batang.

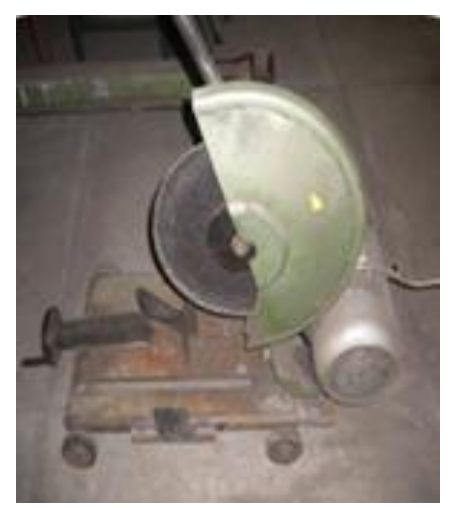

Gambar 6. Gergaji Listrik 


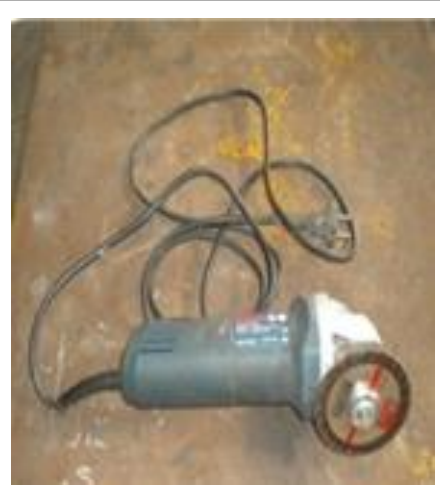

Gambar 7. Gerinda Tangan

\section{Pengukuran dan pemotongan tutup dapur} pemanas

Tutup dapur pemanas terbuat dari plat baja tahan panas dengan tebal $3 \mathrm{~mm}$ dan material tersebut, diukur menggunakan rollmeter dengan ukuran: panjang $1100 \mathrm{~mm}$, lebar 900 $\mathrm{mm}$ dan tebal $3 \mathrm{~mm}$ selanjutnya dilakukan proses pemotongan menggunakan gergaji listrik.

3. Pengukuran dan pemotongan pipa cerobong

Cerobong terbuat dari material baja tahan panas dengan diameter $76,2 \mathrm{~mm}$ dan panjang $500 \mathrm{~mm}$ diukur menggunakan jangka sorong untuk mengukur diameter pipa dan rollmeter mengukur panjang pipa dan selanjutnya dipotong menggunakan gergaji listrik.

4. Proses pengelasan rangka dapur pemanas terbuka

Rangka dapur pemanas terbuka terbuat dari besi profil L (gambar 7) setelah dilakukan proses pengelasan menggunakan las busur listrik elektroda terbungkus (Gambar 8). Fungsi rangka dapur pemanas terbuka sebagai bodi agar dapur pemanas membentuk persegi panjang dengan ukuran: panjang $1100 \mathrm{~mm}$, lebar $900 \mathrm{~mm}$ dan tinggi $700 \mathrm{~mm}$.

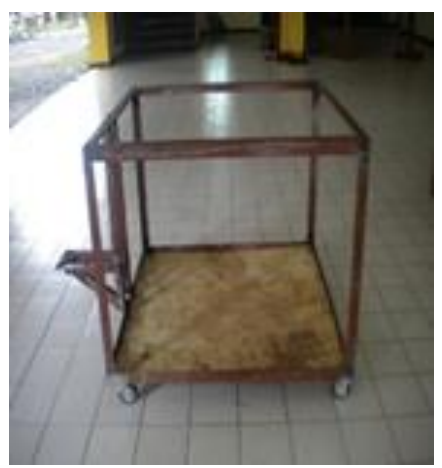

Gambar 7. Rangka Dapur Pemanas Terbuka

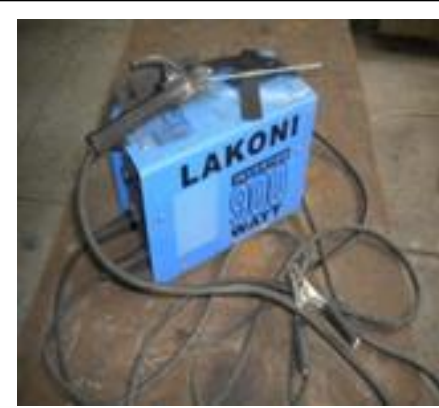

Gambar 8. Mesin Las Busur Listrik Elektroda Terbungkus

\section{Perakitan dapur pemanas}

Besi profil L yang telah dipotong-potong selanjutnya proses penyambungan dengan proses pengelasan jenis mesin las listrik elektroda terbungkus dengan diameter kawat elektroda 1,2 $\mathrm{mm}$, sehingga membentuk rangka dapur pemanas dan rangka blower dilas menyatu dengan rangka dapur pemanas. Rangka dapur pemanas yang telah terbentuk selanjutnya dipasang bata tahan api SK 34 sejumlah 100 buah yang diberi semen tahan api sebagai bahan perekat dan dinding dalam dilapisi dengan Castable material sebagai penguat. Pada dinding luar bata tahan api dilapisi bata merah sebanyak 200 buah yang dicampur semen portland dicampur pasir sebanyak $40 \mathrm{~kg}$ dan air. Pada bagian dasar dapur pemanas dipasang kowi terbuat dari bahan bata tahan api sebagai tempat pembakaran arang kayu jati dengan ukuran: panjang $900 \mathrm{~m}$, lebar $700 \mathrm{~mm}$ dan tinggi $700 \mathrm{~mm}$. Gas buang hasil pembakaran arang kayu jati dipasang 2 buah cerobong yang dipasang pada dinding dalam dan luar bata tahan api. Untuk mempermudah proses pemindahan dapur pemanas (portable) di bagian dasar dapur pemanas dipasang roda rol dengan diameter 100 mm sebanyak 4 (empat) buah yang disambung dengan las listrik. Pekerjaan selanjutnya pemasangan tutup dapur pemanas di atas permukaan dapur pemanas dengan dipasang 2 (dua) buah engsel, sehingga mempermudah membuka dan menutup saat dapur pemanas bekerja.

\section{Perbaikan desain dapur pemanas}

Dapur pemanas terbuka tanpa cerobong (Gambar 1) diperbaiki konstruksinya dengan model tertutup yang dilengkapi dengan cerobong ganda (Gambar 9). 


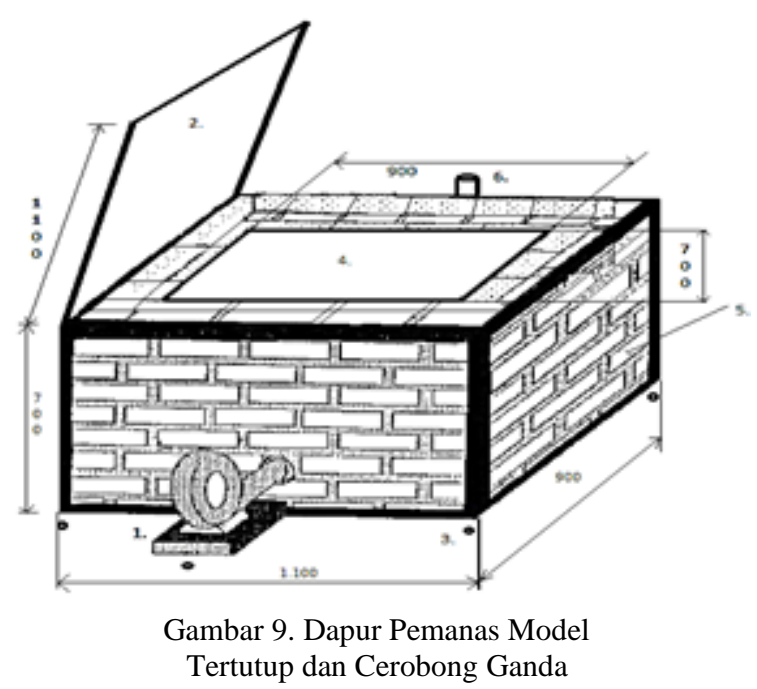

Ukuran-ukuran dapur pemanas:

1. Panjang dapur $: 1.100 \mathrm{~mm}$

2. Panjang tutup dapur : $1.100 \mathrm{~mm}$

3. Lebar dapur $\quad: 900 \mathrm{~mm}$

4. Lebar tutup dapur : $900 \mathrm{~mm}$

5. Tinggi dapur $: 700 \mathrm{~mm}$

6. Panjang kowi : $900 \mathrm{~mm}$

Keterangan Gambar 9:

1. Blower

2. Penutup dapur

3. Peluncur

4. Kowi

5. Bata tahan api

6. Cerobong Ganda

Hasil pembuatan dapur pemanas (Gambar 10 dan Gambar 11) selanjutnya dilanjutkan uji coba dengan arang kayu jati dan material milik mitra dan material dalam keadaan berpijar (Gambar 12).

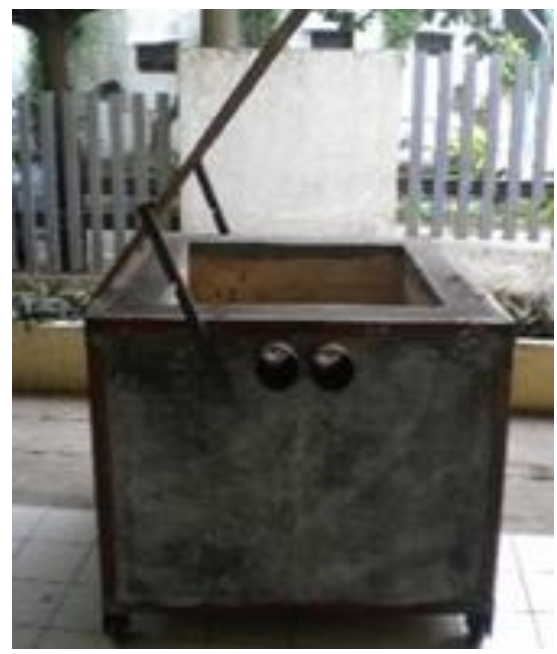

Gambar 10. Letak Cerobong Ganda

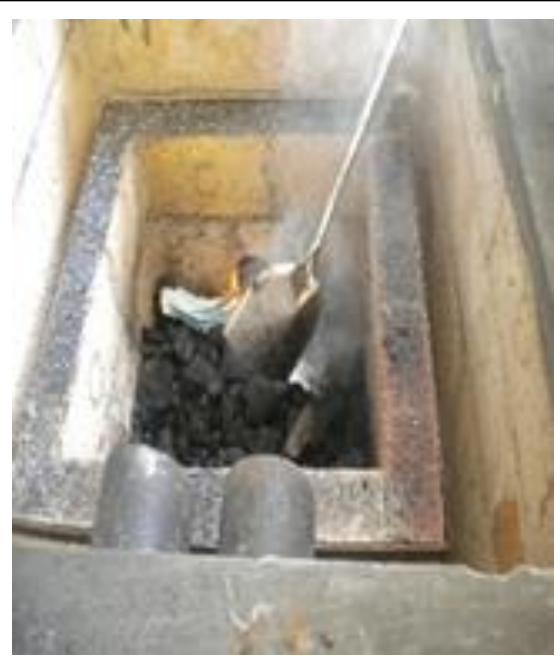

Gambar 11. Letak Arang Kayu Jati dalam Kowi

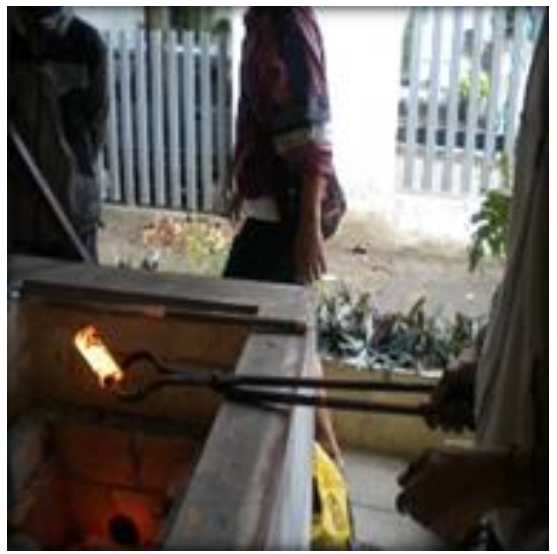

Gambar 12. Logam Hasil Proses Pemanasan

Uji coba dapur pemanas terbuka

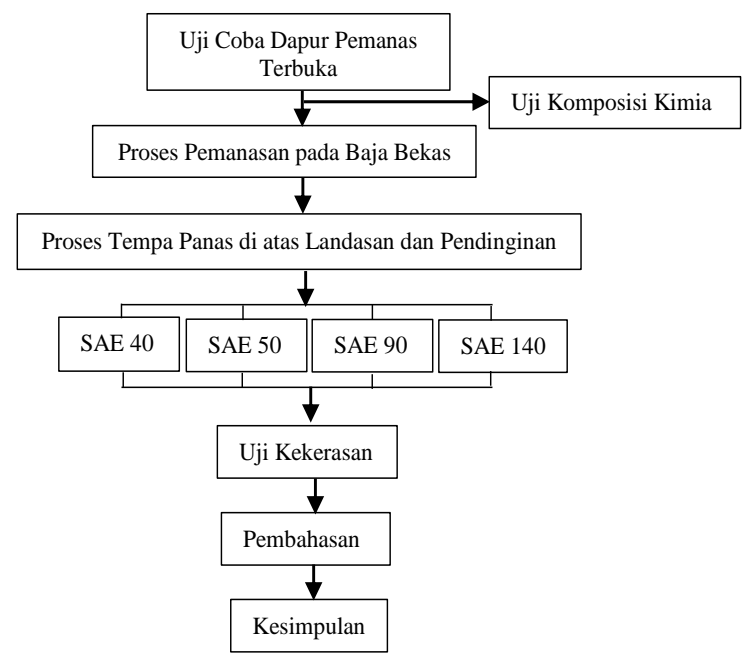

Gambar 13. Langkah-langkah Uji Coba

Uji komposisi kimia

Material logam yang digunakan untuk uji coba menggunakan dua jenis logam bekas yang mempunyai sifat dan komposisi kimia berbeda. Untuk mengetahui komposisi kimia menggunakan alat Quantometer 3460/MA 
(Gambar 14) dan data hasil uji komposisi kimia (Tabel 1).

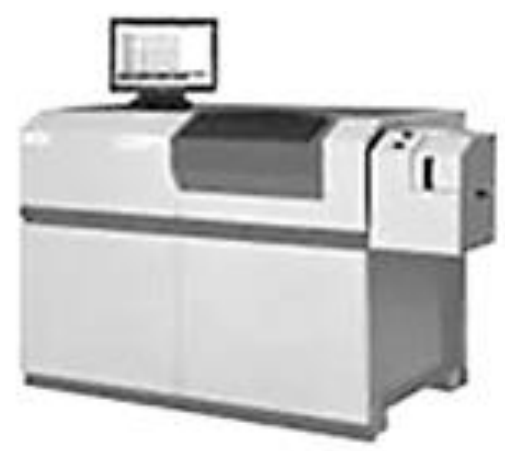

Gambar 14. Quantometer 3460/MA

Tabel 1. Data Hasil Uji Komposisi Kimia pada Baja bekas sebelum Proses Tempa Panas

\begin{tabular}{|c|c|c|c|}
\hline No & Jenis Material & Unsurr Kimia & Komposisi Kimia \\
\hline 1 & \multirow{9}{*}{$\begin{array}{l}\text { Baja Karbon Rendah } \\
\text { (baja bekas) }\end{array}$} & Carbon $(\mathrm{C})$ & $0,132 \%$ \\
\hline 2 & & Mangan (Mn) & $0,365 \%$ \\
\hline 3 & & Pospor $(\mathrm{P})$ & $0,007 \%$ \\
\hline 4 & & Sulfur (S) & $0,005 \%$ \\
\hline 5 & & Silikon $(\mathrm{Si})$ & $0,192 \%$ \\
\hline 6 & & Aluminium $(\mathrm{Al})$ & $0,033 \%$ \\
\hline 7 & & Khrom $(\mathrm{Cr})$ & $0,011 \%$ \\
\hline 8 & & Cuprum $(\mathrm{Cu})$ & $0,012 \%$ \\
\hline 9 & & $\operatorname{Besi}(\mathrm{Fe})$ & $99,19 \%$ \\
\hline 1 & \multirow{9}{*}{$\begin{array}{l}\text { Baja Karbon Tinggi } \\
\text { (baja bekas) }\end{array}$} & Carbon $(\mathrm{C})$ & $1,261 \%$ \\
\hline 2 & & Mangan (Mn) & $0,311 \%$ \\
\hline 3 & & Pospor (P) & $0,013 \%$ \\
\hline 4 & & Sulfur (S) & $0,015 \%$ \\
\hline 5 & & Silikon (Si) & $0,230 \%$ \\
\hline 6 & & Aluminium $(\mathrm{Al})$ & $0,007 \%$ \\
\hline 7 & & Khrom $(\mathrm{Cr})$ & $0,041 \%$ \\
\hline 8 & & Cuprum $(\mathrm{Cu})$ & $0,092 \%$ \\
\hline 9 & & $\operatorname{Besi}(\mathrm{Fe})$ & $97,96 \%$ \\
\hline
\end{tabular}

Sumber: PT. ISPAT INDO Desa Kedungturi, Taman Sidoarjo Po Box 1083 Surabaya

\section{Uji kekerasan}

Uji kekerasan pada material setelah proses tempa panas dan proses penyepuhan diuji menggunakan rockwell hardness tester dengan indentor bola baja diameter 1/16 inch, beban mayor $100 \mathrm{~kg}$ dan beban minor $10 \mathrm{~kg}$ (Gambar 15). Hasil uji kekerasan (Tabel 2).

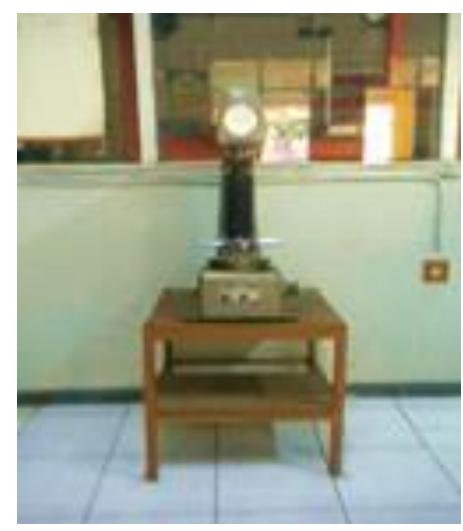

Gambar 15. Mesin Uji Kekerasan
Tabel 2. Data Hasil Uji Kekerasan pada Baja bekas Setelah Proses Tempa Panas

\begin{tabular}{|c|c|c|c|c|}
\hline No & $\begin{array}{c}\text { Media } \\
\text { Penyepuhan }\end{array}$ & $\begin{array}{c}\text { Temperatur } \\
\text { Dapur Tertutup } \\
\left({ }^{\circ} \mathrm{C}\right) \\
\end{array}$ & $\begin{array}{c}\text { Angka Kekerasan } \\
\text { (HRB) }\end{array}$ & $\begin{array}{c}\text { Rata-2 Angka } \\
\text { Kekerasan } \\
\text { (HRB) }\end{array}$ \\
\hline 1 & SAE 40 & 925 & $\begin{array}{l}89 \\
87 \\
86 \\
92 \\
84 \\
86 \\
88 \\
88 \\
89 \\
86 \\
\end{array}$ & 88 \\
\hline 2 & SAE 50 & 925 & $\begin{array}{l}90 \\
87 \\
86 \\
86 \\
86 \\
87 \\
87 \\
86 \\
86 \\
89\end{array}$ & 87 \\
\hline 3 & SAE 90 & 925 & $\begin{array}{l}85 \\
86 \\
86 \\
88 \\
86 \\
86 \\
86 \\
86 \\
86 \\
87 \\
\end{array}$ & 86 \\
\hline 4 & SAE 140 & 925 & $\begin{array}{l}85 \\
86 \\
84 \\
85 \\
86 \\
85 \\
86 \\
84 \\
85 \\
85\end{array}$ & 85 \\
\hline
\end{tabular}

Sumber: Lab. Uji Logam JTM-FT.UNMER Malang

\section{Uji pengamatan struktur mikro}

Uji pengamatan struktur mikro dilakukan pada tujuan untuk mengetahui: (a) batas antara baja karbon rendah dengan baja karbon tinggi, (b) besar butir, (c) jenis fasa hasil proses tempa panas dan proses penyepuhan dengan minyak pelumas jenis: SAE 40, SAE 50, SAE 90 dan SAE 140. Uji pengamatan struktur mikro menggunakan mikroskop logam dengan pembesaran 400 kali (gambar 16).

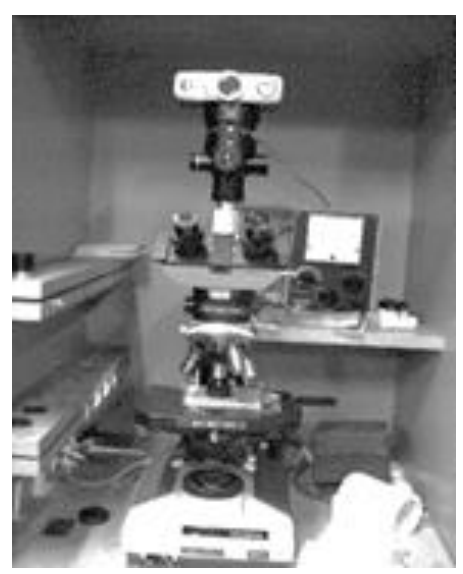

Gambar 16. Mikroskop Logam 
Tabel 3.Data Hasil Uji Pengamatan Struktur Mikro Setelah Proses Tempa Panas

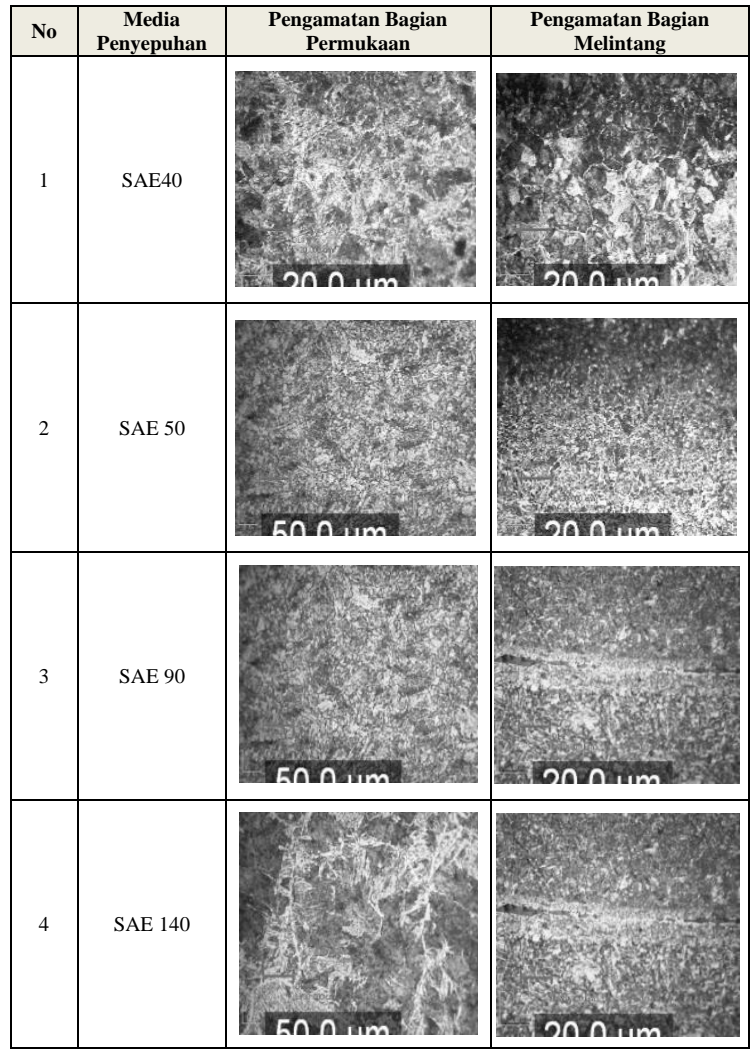

Sumber: Lab. Uji Logam JTM-FT.UNMER Malang

\section{HASIL DAN PEMBAHASAN}

Dapur pemanas terbuka yang dirancang berbentuk persegi panjang dengan dinding terbuat dari material bata tahan api dan bata merah dengan ukuran: (a) panjang $1.100 \mathrm{~mm}$, (b) lebar $900 \mathrm{~mm}$, dan (c) tinggi $700 \mathrm{~mm}$. Dapur pemanas terbuka berfungsi untuk proses pemanasan pada logam, khususnya Pandai Besi di desa Talang Suko Kedok RT 01 RW 03 Kedok Kabupaten Malang. Teknologi proses yang dilakukan oleh pandai besi meliputi: (a) pembakaran, (b) pemanasan, (c) tempa panas, dan (d) pendinginan. Pembakaran merupakan proses pengerjaan untuk memperoleh energi panas (heat energy) dengan cara membakar arang kayu jati sebanyak $20 \mathrm{~kg}$ di dalam kowi sampai di atas temperatur rekristalisasi $925^{\circ} \mathrm{C}$. Pemanasan merupakan proses pengerjaan memanaskan logam di dalam kowi sampai di atas temperatur rekristalisasi $925^{\circ} \mathrm{C}$. Temperatur rekristalisasi merupakan perubahan struktur kristal akibat pemanasan pada suhu kritis di mana suhu kritis pada baja karbon rendah dan baja karbon tinggi yang akan ditempa panas adalah pada $723^{\circ} \mathrm{C}$ (Gambar 17), sehingga dapat diartikan bahwa temperatur rekristalisasi merupakan suatu proses di mana butir logam yang terdeformasi digantikan oleh butiran baru yang tidak terdeformasi yang intinya tumbuh sampai butiran asli termasuk di dalamnya (Surdia, T. 1995)

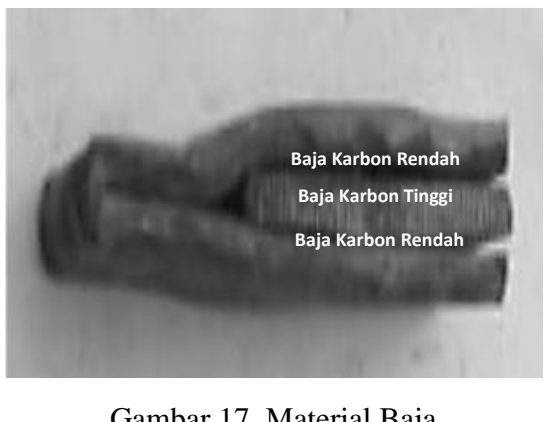

Tempa panas merupakan proses pembentukan logam dengan cara menempa (dipukul) secara manual menggunakan palu dengan berat 3 s.d 5 $\mathrm{kg}$ secara berulang-ulang yang berfungsi untuk memberikan gaya $(\mathrm{F})$ dari luar (external force) sampai baja karbon rendah dan baja karbon tinggi menyatu (Gambar 18) (Akbar, N., dkk., 2017).

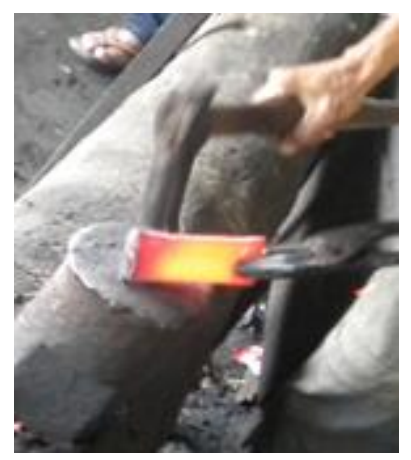

Gambar 18. Proses Tempa Panas

Proses penyepuhan merupakan proses pendinginan cepat untuk mendinginkan logam yang telah dilakukan proses tempa panas. Sebagai media pendinginan menggunakan minyak pelumas jenis SAE SAE 40, SAE 50, SAE 90, SAE 140 dengan tujuan memperbaiki sifat mekanis (sifat kekerasan). Angka kekerasan setiap hasil proses pendinginan secara umum cenderung menurun, sehingga hasil tempa panas semakin ulet dan tidak rapuh. Angka kekerasan tertinggi pada pendinginan oli SAE 40 sebesar $88 \mathrm{HR}_{\mathrm{B}}$ (Tabel 2) dan angka kekerasan terendah pada pendinginan oli SAE 140 sebesar $85 \mathrm{HR}_{\mathrm{B}}$ (Tabel 4). Angka kekerasan semakin menurun disebabkan oleh viskositas oli semakin kental, sehingga menghambat laju pendinginan (cooling rate) semakin lambat akibatnya besar butir semakin besar atau kasar (coarse). Besar butir semakin besar, maka material yang telah mengalami proses pemanasan lebih mudah ditempa. Pengamatan struktur mikro pada bagian 
permukaan hasil tempa panas pendinginan jenis oli: SAE 40, SAE 50, SAE 90, SAE 140 dengan pembesaran $100 \mathrm{x}$ secara umum terbentuk fasa ferit $(\alpha)$ (warna terang) lebih dominan dibanding dengan fasa perlit $\left(\alpha+\mathrm{Fe}_{3} \mathrm{C}\right)$ (warna gelap) (tabel 5 s.d 8). Pengamatan struktur mikro pada bagian melintang hasil tempa panas pendinginan jenis oli SAE 40, SAE 50, SAE 90, SAE 140 dengan pembesaran $100 \mathrm{x}, 200 \mathrm{x}, 400 \mathrm{x}$ secara umum baja karbon rendah dan baja karbon tinggi telah menyatu (tabel 5 s.d 8). Fasa $\alpha$ mempunyai sifat ulet dan kekerasannya rendah dan fasa $\alpha+$ $\mathrm{Fe}_{3} \mathrm{C}$ mempunyai sifat keras dan getas. Pada pendinginan jenis oli: SAE 40, SAE 50, SAE 90, SAE 140 tidak terbentuk fasa martensit yang sifatnya sangat keras dan getas dibanding fasa $\alpha$ $+\mathrm{Fe}_{3} \mathrm{C}$, hal ini disebabkan pada saat proses pendinginan seluruh jenis oli fasa austenit $(\gamma)$ tidak dapat bertransformasi menjadi fasa martensit. Fasa $\gamma$ mempunyai sel satuan Kubus Pemusatan Sisi (KPS) atau face centered cubic (FCC) yang mempunyai sifat ulet dan kuat tetapi mudah untuk dilakukan proses pembentukan. Fasa $\gamma$ terjadi di atas temperatur $723^{\circ} \mathrm{C}$ atau pada temperatur $912^{\circ}$ s.d $1394^{\circ} \mathrm{C}$, di mana fasa ini merupakan larutan padat (solid solution) antara $\mathrm{Fe}$ dan $\mathrm{C}$ dengan kelarutan $\mathrm{C}$ maksimum $2 \%$. Fasa $\gamma$ mempunyai sifat: lunak, ulet, kuat dan ketangguhannya sangat tinggi serta tidak stabil pada temperatur kamar (room temperature). Fasa $\alpha$ mempunyai sel satuan Kubus Pemusatan Ruang (Body Centered Cubic) (BCC) pada temperatur di bawah $910^{\circ} \mathrm{C}$. BCC merupakan larutan padat (solid solution) terdiri atas beberapa atom $\mathrm{C}$ yang ada pada besi murni dan kelarutan unsur $\mathrm{C}$ pada fasa $\alpha$ maksimum $0,025 \%$ terjadi di bawah temperatur $723^{\circ} \mathrm{C}$, tetapi pada temperatur kamar kelarutan C sekitar 0,008\%. Fasa $\alpha+\mathrm{Fe}_{3} \mathrm{C}$ merupakan campuran eutektoid terdiri atas fasa $\alpha$ dan fasa $\mathrm{Fe}_{3} \mathrm{C}$ yang mengandung $0,8 \% \quad \mathrm{C}$ yang terbentuk pada temperatur $723^{\circ} \mathrm{C}$ dengan sel satuan BCC (Smith, W.F. 1990).

\section{SIMPULAN}

a. Dapur pemanas terbuka dengan cerobong ganda menghasilkan temperatur $925^{\circ} \mathrm{C}$ lebih tinggi dibanding dapur pemanas tertutup hanya mampu mencapai temperatur panas $720^{\circ} \mathrm{C}$.

b. Kekerasan logam hasil tempa panas tertinggi $88 \mathrm{HR}_{\mathrm{B}}$ dengan pendinginan oli SAE 40 dan terendah $85 \mathrm{HR}_{\mathrm{B}}$ dengan pendinginan oli $\mathrm{SAE}$ 140.

\section{DAFTAR PUSTAKA}

Akbar, N. Andrijono, R. D., Mardjuki, M., 2017, Variasi Media Pendinginan Terhadap Kekerasan Material Logam Hasil Tempa Tempa Panas Pandai Besi, Transmisi, Vol. 13 No. 1, Hal. 145-156, Teknik Mesin Universitas Merdeka Malang

Askeland, D. R., 1984, The Scince and Engeneering of Materials, University of Misouri-Rolla, California, USA.

Avner, S.H., 1987. Introduction to Physical Metallurgy, Singapore: Graw Hill International.

Broek, D., 1986, Elementary Engineering Fracture Mechanics, Kluwer Academic Publisher,Dordrecht, The Netherlands.

Dieter, G,E., 1981. Mechanical Metallurgy. Second Edition. Tokyo: McGraw-Hill International Book Company.

Eko Surojo, Pengaruh Manual Flame Hardening terhadap Kekerasan Hasil Tempa Baja Pegas, Jurnal Mekanika Volume 7 Nomor 2 Maret 2009. Halaman $45-49$.

Furqon, M. 1997. Pengaruh Modifikasi pada Tungku Tradisional Pandai Besi terhadap Unjuk Kerja dan Produktivitas. Lomba Rancang Bangun Teknologi, BPPT.

Hana. U. 2013. Competitive Advantage Achievent Thorugh Innovation and Knowledge

Hosford, W, F, dan Caddel, R, M. 1983, Metal Forming Mechanics and Metalurgy, Prenticehall, Inc.

Jastrzebski, Z. D., 1980, The Nature and Properties of Engeneering Materials, Third editions, New York.

Martin, G, Delgado, M, Novas, J.E, Eruz J (2013). The Moderating Role of Innovation Culture in the Relationship Between Konwledge Assets and Product Innvation. Technological Forecasting and Social Change Journal. 2 (10) : $251-363$.

Nouruzy, A, Dalfard, V,M, Azhdari, B, Nazari Shirkouhi, S, Rezazadeh, A (2013). Transformational Leadership, Knowledge Management, Organizational Innovation and Organizational Innovation and Organizational Performance, The 
International Journal of Advanced

Manufacturing Technology. 2 (4) : $5-8$.

Polukhin, P. 1977. Metal Process Engineering. Fourth Printing. Mir Publishers: Moscow.

Smith, W.F. 1990. Principles of Materials Science and Enginnering. Second Edition. McGraw-Hill International Editions.

Sugiyono, A. 2000. Pembuatan, Pemasangan dan Pengoperasian Tungku Perlakuan Panas. Direktorat Teknologi Konversi dan Konservasi Energi Deputi Bidang Teknologi Informasi, Energi, Material dan Lingkungan, BPPT.

Surdia, T. 1995. Pengetahuan Bahan Teknik. PT. Erlangga: Jakarta. 